\title{
Cardiac shockwave therapy improves myocardial function in patients with refractory coronary artery disease by promoting VEGF and IL-8 secretion to mediate the proliferation of endothelial progenitor cells
}

\author{
HONG-YAN CAI ${ }^{1 *}$, LIN LI $^{1 *}$, TAO GUO $^{1}$, YU WANG $^{1}$, TIE-KUN MA $^{2}$, JIAN-MING XIAO $^{1}$, \\ LING ZHAO $^{1}$, YIN FANG ${ }^{3}$, PING YANG ${ }^{1}$ and $\mathrm{HU} \mathrm{ZHAO}^{1}$ \\ Departments of ${ }^{1}$ Cardiology and ${ }^{2}$ Nuclear Medicine, First Hospital of Kunming Medical University, Kunming, Yunnan 650032; \\ ${ }^{3}$ Department of Medical Statistics, Second Hospital of Kunming Medical University, Kunming, Yunnan 650101, P.R. China
}

Received September 26, 2014; Accepted August 26, 2015

DOI: $10.3892 /$ etm.2015.2820

\begin{abstract}
Cardiac shockwave therapy (CSWT) is a potential and effective remedy to promote revascularization in the ischemic myocardium of patients with refractory coronary heart disease (CHD). The technique is both safe and non-invasive; however, the underlying molecular mechanism remains unclear. The aim of this study was to evaluate the efficacy of CSWT in treating CHD patients and investigate a potential mechanism. A total of 26 patients with CHD were enrolled in the study, and CSWT was performed over a 3-month period. The efficacy of CSWT was assessed using several clinical parameters. Peripheral blood (PB) was collected prior to and following treatment. The number of circulating endothelial progenitor cells (EPCs) in the PB was counted using a flow cytometer, and the levels of vascular endothelial growth factor (VEGF), interleukin-8 (IL-8), stromal cell-derived factor 1 and matrix metalloproteinase 9 in the $\mathrm{PB}$ were analyzed. Mononuclear cells were isolated from the PB and cultured in vitro. The EPCs and EPC-colony forming units (EPC-CFUs) in the PB mononuclear cell culture were counted using an inverted phase contrast microscope. Following CSWT, the tested clinical parameters were significantly improved. The levels of circulating EPCs, VEGF and IL- 8 in the PB were significantly increased, as were the EPCs and EPC-CFUs from the PB mononuclear cell culture. We suggest that EPC
\end{abstract}

Correspondence to: Professor Tao Guo, Department of Cardiology, First Hospital of Kunming Medical University, 295 Xichang Road, Kunming, Yunnan 650032, P.R. China

E-mail: guotao20@hotmail.com

*Contributed equally

Key words: cardiac shockwave therapy, coronary artery disease, endothelial progenitor cells, vascular endothelial growth factor, interleukin-8 proliferation, mediated by VEGF and IL-8 secretion, may be among the potential mechanisms associated with CSWT.

\section{Introduction}

Angiocardiopathy is one of the most dangerous diseases to human health, accounting for $50 \%$ of mortality in developed countries (1). Coronary heart disease (CHD) may be the most lethal form of cardiovascular disease. Statistical data from the World Health Organization indicates that CHD will become the most significant cause of mortality worldwide by 2020 (2-4). Thrombolytic therapy, coronary artery bypass grafting (CABG), percutaneous coronary intervention (PCI) and angiogenesis therapy are therapeutic options. These therapies enable revascularization of the ischemic myocardium and markedly improve the symptoms of CHD; however, they are associated with certain shortcomings. For example, certain patients are not able to undergo the risk of CABG and PCI, while others may not be able to afford the treatment. Alternative therapies targeting angiogenesis, including stem cell therapy, remain in development and are not yet routinely used in clinical practice.

Cardiac shockwave therapy (CSWT) is a novel, noninvasive approach that has been shown to ameliorate myocardial ischemia and improve cardiac function (5-9). In early clinical trials CSWT was found to alleviate angina and improve cardiopulmonary fitness in patients with myocardial ischemia $(6,9)$. Furthermore, findings from previous studies suggest that CSWT can reduce the ischemic burden and relieve angina by enhancing angiogenesis and revascularization in the ischemic myocardium (5-7). Animal studies in vivo and human clinical studies have shown that the low-energy pulse waves generated by CSWT induce a 'cavitation effect' (violent collapse of micron-sized bubbles within and outside cells), exerting a mechanical shear force on myocardial and vascular endothelial cells. It has been reported that CSWT promotes revascularization and improves ventricular remodeling in an acute myocardial infarction pig model $(5,9)$. Furthermore, results of our previous study showed that CSWT improved the clinical symptoms of CHD in a randomized, double-blind 
experiment (10); however, although CSWT has shown promising efficacy against the symptoms of CHD, the mechanism is not clear. Two different studies previously revealed that CSWT upregulated the vascular endothelial growth factor (VEGF) level in a chronic myocardial ischemia porcine model $(11,12)$. Based on previous studies, we hypothesized that CSWT would induce VEGF, interleukin-8 (IL-8), stromal cell-derived factor 1 (SDF-1) and matrix metalloproteinase 9 (MMP-9) secretion in CHD patients, and that the increase in those cytokines would accelerate the proliferation, differentiation and recruitment of endothelial progenitor cells (EPCs), promote revascularization in the ischemic myocardium and improve cardiac function. The aim of this study was to test this hypothesis.

\section{Patients and methods}

Patients. A total of 23 male and 3 female patients, who were admitted to the Cardiology Department of the First Hospital of Kunming Medical University (Kunming, China) between December 2008 and December 2011, were enrolled in this study. The age range of the patients was 46-78 years (mean, $63 \pm 10$ years), and the average body mass index was $23.86 \mathrm{~kg} / \mathrm{m}^{2}$. The patients had been diagnosed with CHD for between 1 and 16 years. Comorbidities included hypertension $(n=19)$, diabetes mellitus $(n=7)$, hyperlipidemia $(n=4)$, chronic renal inadequacy $(n=3)$ and colitis gravis $(n=1)$. One patient had undergone $\mathrm{CABG}$ and 12 had undergone PCI. The remaining patients had not been treated with coronary revascularization due to poor economic conditions, technical limitations and religious reasons. Although all the patients had received standard medical treatment, they all still suffered from chest discomfort and had poor exercise tolerance; furthermore, all the patients had been hospitalized $>2$ times within 1 year due to myocardial ischemia. Patients with a myocardial infarction within the past 3 months, cardiac thrombus, chronic obstructive pulmonary disease, pulmonary embolism, New York Heart Association (NYHA) heart function IV and malignancy were excluded from this study.

CSWT procedure. The CSWT was performed as described in our previous report (10). Briefly, patients were placed in a supine position and rested in a non-agitated state during the procedure. The electrocardiogram (ECG), blood pressure, breathing and blood oxygen saturation of each patient were simultaneously monitored. An ultrasound probe was used to identify the target myocardial regions, and the water cushion was lowered to contact the chest. Shockwaves (depth, $150 \mathrm{~mm}$; aperture angle, $48^{\circ}$ ), triggered by the $\mathrm{R}$ wave on the ECG, were voluntarily released by the parabolic reflector at the absolute refractory period of electrical activity. Wave energy was gradually increased in all patients (maximum, $0.09 \mathrm{~mJ} / \mathrm{mm}^{2}$ in patients exhibiting no chest pain). The regional targeting of shockwave transmission to the myocardium was finely adjusted using microcontrols. A range of control levels $(+1,+2,+3,0,-1$, -2 and -3$)$ enabled the incremental modulation of the angle $\left(6^{\circ}\right)$ and distance $(2.5 \mathrm{~mm})$ along the treatment area. Each ischemic region was treated at 9 points $(-1,0,+1$ pairs). During the treatment period, the patients underwent close monitoring for vital signs and symptoms, including palpitations, chest pain, breathing difficulty and dizziness. The therapy schedule was devised based on the recommendations of the Cardiovascular Center of Munich, Germany and the Cardiovascular Center of the Kyushu University Graduate School of Medical Sciences, Fukuoka, Japan. The CSWT regimen was conducted over a 3-month period at 3-week intervals. CSWT sessions were administered during the first week of the month on the first, third and fifth day for 3 months, for a total of 9 therapies per patient. The efficacy of CSWT was assessed using the Canadian Cardiovascular Society (CCS) angina scale, NYHA class, Seattle Angina Questionnaire (SAQ) scale, 6-min walk test (6MWT) and nitroglycerin dosage prior to and following 30 days of CSWT $(13,14)$.

Analysis of VEGF, IL-8, SDF-1 and MMP-9 levels in the peripheral blood $(P B)$. A 2-ml blood sample was drawn from the arm vein of all patients 1 day before and 30 days after the CSWT. Blood plasma was prepared by centrifugation $(850 \mathrm{x} \mathrm{g})$ at $4^{\circ} \mathrm{C}$ for $10 \mathrm{~min}$. The levels of VEGF, IL-8, SDF-1 and MMP-9 were measured using ELISA kits from R\&D Systems GmbH (Wiesbaden-Nordenstadt, Germany).

Culture and identification of EPCs among PB mononuclear cells. PB mononuclear cells were prepared by density gradient centrifugation using lymphocyte separation liquid (Sigma-Aldrich, St. Louis, MO, USA) (15). PB mononuclear cells were suspended in EGM-2-MV microvascular endothelial cell growth medium (Lonza Walkersville, Inc., Walkersville, MD, USA) following centrifugation and then inoculated at a density of $5 \times 10^{6}$ cells/well in human fibronectin-coated 6-well plates (Corning, Inc., Corning, NY, USA) and cultured in a $37^{\circ} \mathrm{C}$ incubator with $5 \% \mathrm{CO}_{2}$ and $100 \%$ humidity. After 4 days of culture, non-adherent cells were washed away using phosphate-buffered saline (PBS). Three visual fields under the inverted phase contrast microscope were randomly selected to count the EPCs and EPC-colony forming units (EPC-CFUs) after 7 days of culture. One experimenter and one experienced lab technician performed the count in a blinded manner to evaluate repeatability (variation coefficient, $<10 \%$ ). In addition, after 7 days of culture the adherent cells were treated with $2.4 \mathrm{mg} / \mathrm{l}$ Dil-labeled acetylated low-density lipoprotein (Dil-acLDL; Molecular Probes Life Technologies, Carlsbad, CA, USA) for $1 \mathrm{~h}$ at $37^{\circ} \mathrm{C}$ and fixed using $2 \%$ paraformaldehyde. After washing, the EPCs were incubated with $10 \mathrm{mg} / \mathrm{ml}$ fluorescein isothiocyanate-Ulex europaeus agglutinin-1 (FITCUEA-1; Sigma-Aldrich) at $48^{\circ} \mathrm{C}$ for $30 \mathrm{~min}$. The incorporation of Dil-acLDL and binding of FITCUEA-1 were detected using a confocal microscope (Leica Microsystems GmbH, Wetzlar, Germany).

Detection of circulating EPCs. The detection of EPCs in the circulating blood was performed as described in a previous study (16). In brief, $100 \mu 1$ blood was immunostained with monoclonal antibodies against human CD34 (peridinin chlorophyll-conjugated; 10:1; PC1211; Becton Dickinson, Franklin Lakes, NJ, USA) and against human VEGF receptor 2 (VEGFR2; 50:1; A5441; Sigma-Aldrich), followed by a phycoerythrin-conjugated secondary antibody (Beckman Coulter, Inc., Brea, CA, USA). Isotype-identical antibodies served as controls (10:1; AK1035; Becton Dickinson). Following incu- 
Table I. Evaluation of the clinical curative effect of CSWT.

\begin{tabular}{lccccc}
\hline Time-point & 6MWT $(\mathrm{m})$ & $\begin{array}{c}\text { NYHA } \\
\text { class }\end{array}$ & $\begin{array}{c}\text { CCS angina } \\
\text { scale }\end{array}$ & $\begin{array}{c}\text { SAQ } \\
\text { scale }\end{array}$ & $\begin{array}{c}\text { Nitroglycerin dosage } \\
(\text { doses per week) }\end{array}$ \\
\hline Pre-CSWT & $360.69 \pm 116.79$ & $1.85 \pm 0.21$ & $1.85 \pm 0.15$ & $67.58 \pm 13.03$ & $1.00 \pm 0.27$ \\
Post-CSWT & $434.15 \pm 86.29^{\mathrm{a}}$ & $1.23 \pm 0.08^{\mathrm{a}}$ & $1.19 \pm 0.08^{\mathrm{b}}$ & $77.54 \pm 10.84^{\mathrm{a}}$ & $0.50 \pm 0.19^{\mathrm{a}}$ \\
\hline
\end{tabular}

${ }^{\mathrm{a}} \mathrm{P}<0.01$ and ${ }^{\mathrm{b}} \mathrm{P}<0.001$, compared with pre-CSWT. Data are presented as the mean \pm standard deviation $(\mathrm{n}=26)$. CSWT, cardiac shockwave therapy; 6MWT, 6-min walk test; NYHA, New York Heart Association; CCS, Canadian Cardiovascular Society angina scale; SAQ, Seattle Angina Questionnaire.

Table II. Effect of CSWT on the VEGF, IL-8, SDF-1 and MMP-9 levels in the peripheral blood.

\begin{tabular}{lcccc}
\hline Time-point & VEGF $(\mathrm{pg} / \mathrm{ml})$ & IL-8 $(\mathrm{pg} / \mathrm{ml})$ & SDF-1 $(\mathrm{pg} / \mathrm{ml})$ & $\mathrm{MMP}-9(\mathrm{ng} / \mathrm{ml})$ \\
\hline Pre-CSWT & $20.26 \pm 19.85$ & $21.81 \pm 5.94$ & $2,750.87 \pm 636.74$ & $19.66 \pm 3.96$ \\
Post-CSWT & $155.19 \pm 24.67^{\mathrm{a}}$ & $149.70 \pm 44.11^{\mathrm{a}}$ & $2,700.47 \pm 415.19$ & $18.55 \pm 3.78$ \\
\hline
\end{tabular}

${ }^{\mathrm{a}} \mathrm{P}<0.01$, compared with pre-CSWT. Data are presented as the mean \pm standard deviation $(\mathrm{n}=26)$. CSWT, cardiac shockwave therapy; VEGF, vascular endothelial growth factor; IL-8, interleukin-8; SDF-1, stromal cell-derived factor 1; MMP-9, matrix metalloproteinase 9.

bation, cells were lysed, washed with PBS and fixed in 4\% paraformaldehyde; after the exclusion of debris and platelets, 70,000 events were analyzed using a FACSCalibur Flow Cytometer (Becton Dickinson).

Clinical follow-up. The patients were followed-up for 4 months after the last CSWT appointment through outpatient visits, hospital visits and telephone conservations. During follow-up, the therapy scheme was selected according to the state of the illness. If the vessels were not seriously blocked, expectant treatment was administered. If the vessels was seriously damaged and blocked, surgical treatment was advised (CABG and PCI).

Ethical approval. This study was authorized by the Medical Ethics Committee of Kunming Medical University in December 2008. All 26 patients were informed about the details and procedures involved in the CSWT. Informed written consent was obtained from each patient prior to CSWT.

Statistical analysis. Continuous variables are expressed as the mean \pm standard deviation and categorical variables are expressed as percentages. Nonparametric variables are expressed as the median (interquartile range). The pre-treatment and post-treatment values were compared using a paired t-test. Statistical analyses were performed using SPSS 15.0 statistical software (SPSS, Inc., Chicago, IL, USA). All statistical tests were two-sided, and $\mathrm{P}<0.05$ was considered to indicate a statistically significant difference.

\section{Results}

Efficacy of CSWT. After 3 months of CSWT, the results of the $6 \mathrm{MWT}$ and the SAQ scale score were found to have increased significantly $(\mathrm{P}<0.01)$. The NYHA class and CCS angina scale score were observed to have reduced significantly compared with the pre-CSWT values $(\mathrm{P}<0.01)$. The frequency of weekly nitroglycerin use declined by $50 \%$ (1.00 vs. 0.50 , pre-treatment and post-treatment) (Table I).

Analysis of VEGF, IL-8, SDF-1 and MMP-9 levels in the $P B$. As previously observed in vivo (5), SW therapy has been used to upregulate VEGF expression in a porcine model of chronic myocardial ischemia. In the present study, the VEGF level in the PB in CHD patients was $>7$-fold higher following CSWT compared with the pre-CSWT level $(\mathrm{P}<0.01)$. The post-CSWT IL-8 content also exhibited a marked increased and was found to be $\sim 7$-fold higher than the pre-CSWT value $(\mathrm{P}<0.01)$. By contrast, the levels of SDF-1 and MMP-9 did not show a significant change following CSWT $(\mathrm{P}>0.05)$ (Table II).

PB mononuclear cell culture. The PB mononuclear cells were observed to become larger and clearer after 3 days' culture in vitro, and rod and fusiform cells began to form. Several cell clusters appeared, and colonies were observed in the culture at 7 days. An increased number of differentiating rod and fusiform cells was observed in patients following CSWT compared with patients before CSWT (Fig. 1). Furthermore, an increased size and frequency of EPC-CFUs were noted in the patients subjected to treatment compared with the pre-treatment observations (Fig. 2). The cell count results showed that the numbers of EPCs and EPC-CFUs were significantly increased following CSWT ( $\mathrm{P}<0.001)$ (Figs. 3 and 4). To evaluate the effect of CSWT on the EPCs directly, further comparisons of the circulating EPCs in the PB from patients prior to and following CSWT were conducted. The circulating EPCs (represented by the CD $45^{\text {low }} / \mathrm{CD} 34^{+} / \mathrm{VEGFR} 2^{+}$population) accounted for $1.5 \%$ of the mononuclear cells in the $\mathrm{PB}$ before the CSWT (Fig. 5). After the CSWT, a $0.6 \%$ increase in 

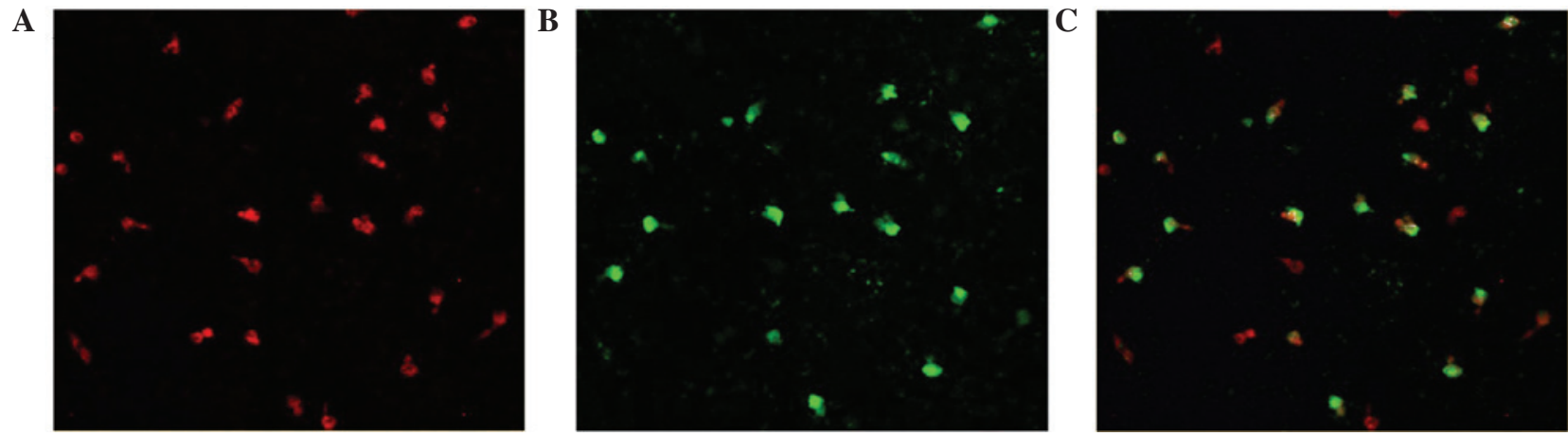

Figure 1. Identification of EPCs. (A) Red indicates cells positively marked with Dil-acLDL (magnification, x200); (B) green indicates cells positively marked with FITCUEA-1 (magnification, x200); (C) overlap of (A) and (B), with yellow indicating the differentiating EPCs (magnification, x200). After 7 days' culure the adherent cells were incubated with Dil-acLDL $(2.4 \mathrm{mg} / \mathrm{l})$ for $1 \mathrm{~h}$ at $37^{\circ} \mathrm{C}$, and the Dil-acLDL uptake was then detected. If uptake was visible, the cells were fixed using $2 \%$ paraformaldehyde and rinsed with phosphate-buffered saline, prior to the addition of FITCUEA-1 (10 mg/l) and incubation for another $1 \mathrm{~h}$ at $37^{\circ} \mathrm{C}$. Images were captured using a confocal laser scanning microscope. EPC, endothelial progenitor cell; Dil-acLDL, Dil-labeled acetylated low-density lipoprotein; FITCUEA-1, fluorescein isothiocyanate-Ulex europaeus agglutinin-1.

A

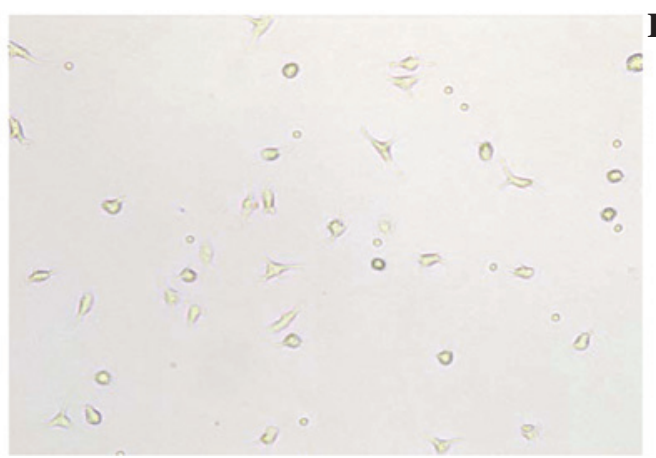

B

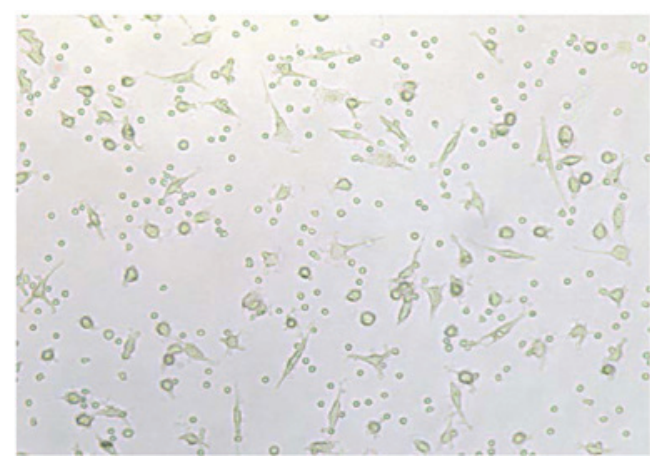

Figure 2. Effect of CSWT on the numbers of EPCs from PB mononuclear cell culture in vitro. (A) Pre-CSWT (magnification, x100); (B) post-CSWT (magnification, x100). Blood was drawn from the upper-arm veins of the patients with coronary heart disease 1 day before CSWT and 30 days after CSWT. PB mononuclear cells were obtained by density gradient centrifugation. After 7 days' culture in vitro, EPCs were counted using an inverted phase contrast microscope. CSWT, cardiac shockwave therapy; EPC, endothelial progenitor cell; PB, peripheral blood.
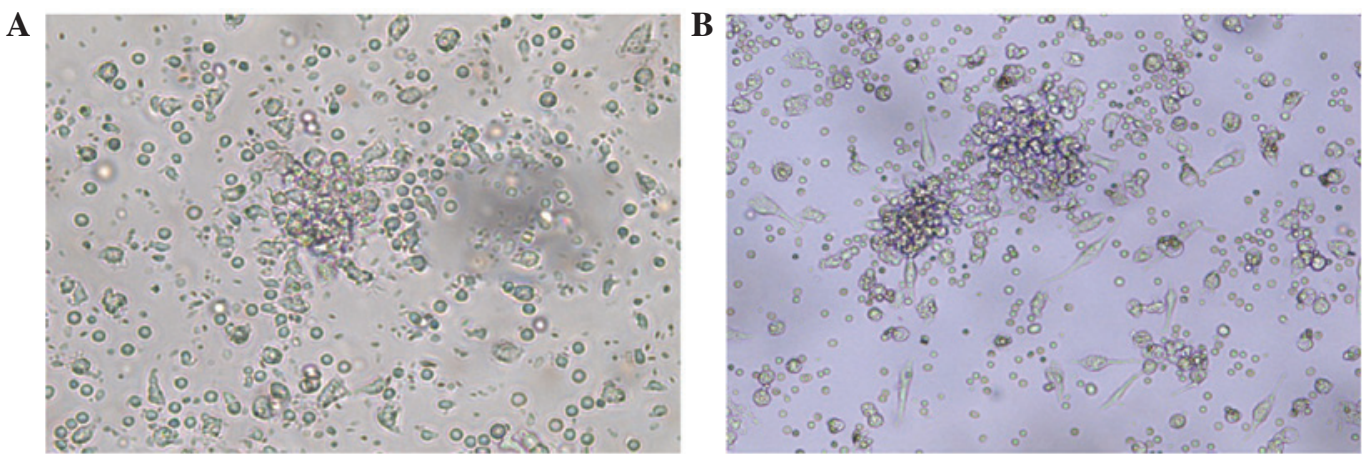

Figure 3. Effect of CSWT on the numbers of EPC-CFUs from PB mononuclear cell culture in vitro. (A) Pre-CSWT (magnification, x100); (B) post-CSWT (magnification, x100). Blood was drawn from the upper-arm veins of the patients with coronary heart disease 1 day before CSWT and 30 days after CSWT. PB mononuclear cells were obtained by density gradient centrifugation. After 7 days' culture in vitro, EPC-CFUs were counted using an inverted phase contrast microscope. CSWT, cardiac shockwave therapy; EPC-CFU, endothelial progenitor cell-colony forming unit; PB, peripheral blood.

the number of $\mathrm{CD} 45^{\text {low }} / \mathrm{CD} 34^{+} / \mathrm{VEGFR} 2^{+}$cells in the $\mathrm{PB}$ was observed (Fig. 5).

Side effects. All patients completed the 9 treatments of CSWT and were followed-up successfully. During the course of treatment, no severe side effects, such as dyspnea, heart failure, heart palpitations, hemorrhage, syncope, embolism and shock, occurred. Although several patients complained of a 'prickly' pain in the chest wall during the first CSWT, this uncomfortable sensation disappeared when the CSWT progressed. Four patients had occasional premature ventricular contractions within the first week of CSWT; however, the blood pressure, heart rate and arterial blood oxygen saturation remained normal. Occasional premature ventricular contractions did not re-occur in the later stages of treatment. None of the patients succumbed within 30 days 


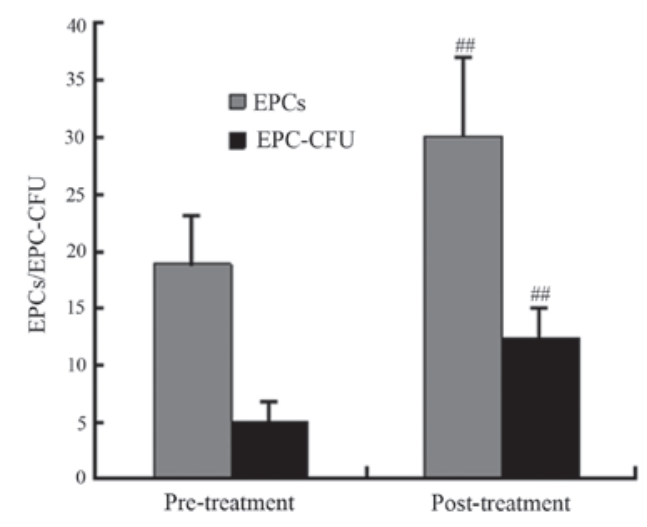

Figure 4. Effect of CSWT on the numbers of EPCs and EPC-CFUs from $\mathrm{PB}$ mononuclear cell culture in vitro. Blood was drawn from the upper-arm veins of the patients with coronary heart disease 1 day before CSWT and 30 days after CSWT. PB mononuclear cells were obtained by density gradient centrifugation and cultured for 7 days in vitro. EPC-CFUs and EPCs were counted in 3 randomly selected visual fields using an inverted phase contrast microscope. Identification of EPCs was performed using a confocal laser scanning microscope. Data are presented as the mean \pm standard deviation $(\mathrm{n}=26) .{ }^{\# /} \mathrm{P}<0.001$, compared with pre-treatment. CSWT, cardiac shockwave therapy; EPC-CFU, endothelial progenitor cell-colony forming unit; $\mathrm{PB}$, peripheral blood.

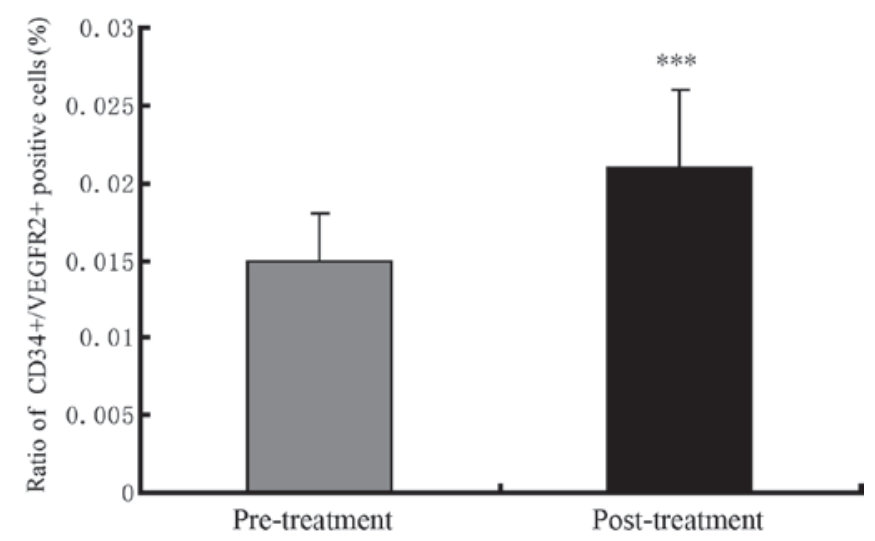

Figure 5. Effect of CSWT on EPCs in the PB. Blood was drawn from the upper-arm veins of the patients with coronary heart disease 1 day before CSWT and 30 days after CSWT. EPCs in the PB were identified using a flow cytometer. The following formula was used: EPCs $(\%)=$ (experimental tube EPCs - control tube EPCs)/mononuclear cells x 100. Data are presented as the mean \pm standard deviation $(n=26){ }^{* * *} \mathrm{P}<0.001$, compared with pre-treatment. CSWT, cardiac shockwave therapy; EPC, endothelial progenitor cell; PB peripheral blood; VEGFR2, vascular endothelial growth factor receptor 2.

of the last CSWT appointment, and none of the patients were re-hospitalized due to heart failure or angina or required PCI or CABG.

\section{Discussion}

The finding that CSWT could produce favorable effects when applied to animal models and patients with CHD was initially made by Nishida et al (5). Since then, a number of studies have been conducted to evaluate the efficacy of CSWT in the treatment of CHD and other diseases $(6,7,9,16-20)$. The results from the majority of the investigations showed that CSWT was effective. In the present study, the CCS angina scale, NYHA class, SAQ scale, nitroglycerin dosage and 6MWT results of the CHD patients showed improvements following CSWT.
Furthermore, the quality of life and exercise tolerance of the patients were enhanced, according to the self-descriptions in the follow-up. No severe negative effects were found during the CSWT or in the follow-up. The statistical outcomes showed that CSWT was safe and effective for the treatment of CHD.

EPCs are not only involved in human embryonic angiogenesis, but also participate in postnatal angiogenesis and endothelial injury recovery. It has been found that $25 \%$ of endotheliocytes in angiogenesis are derived from EPCs (21). The number and migration ability of EPCs are negatively associated with vascular risk factors. It has been reported that EPC numbers in the circulating blood of patients with CHD decline to $\sim 50 \%$ and that the migration ability of the EPCs is also negatively affected $(21,22)$. Under multivariate analysis, age and a positive family history of coronary artery disease remained the only significant independent predictors of a reduced number of EPCs (23). This result indicated that the number of EPCs in patients with CHD or other cardiovascular risk factors may decrease more rapidly with age. Restoring the endothelial lining to normal is critical for slowing or reversing the progression of vascular disease. We hypothesized that the number and function of EPCs could be improved via CSWT in patients with CHD and that the improvement would aid angiogenesis and endothelial repair in these patients, ultimately enhancing cardiac function. The present results showed that the numbers of EPCs and EPC-CFUs among the PB mononuclear cells were significantly increased following CSWT, and the differentiation ability of the EPCs was strengthened. Prior to CSWT, numerous small, characteristic EPCs were observed in the blood samples of the CHD patients. Those cells easily metamorphosed and had a poor ability to further differentiate. In addition, there were few formed EPC colonies. Following CSWT, the EPCs and EPC-CFUs increased in number, and differentiation of the rod and fusiform cells increased. These visible changes were induced by CSWT, and the results were consistent with the findings of Igarashi et al (24) and Thurston et al (25). The number of circulating EPCs also increased markedly following CSWT in the present study. By contrast, Kikuchi et al (17) found that the number of circulating EPCs in samples from 8 patients with CHD exhibited minimal change following CSWT. It is possible that these differences were due to the different sampling time. In the present study, the blood samples were taken 30 days after the last CSWT, while Kikuchi et al examined the EPC numbers $24 \mathrm{~h}$ after the last CSWT. The circulating EPCs may not have had time to undergo perceptible changes only $24 \mathrm{~h}$ after CSWT in the study by Kikuchi et al.

Since it was observed in the present study that CSWT induced EPC differentiation and proliferation, a further investigation into the reasons underlying the phenomenon would be beneficial to reveal the mechanism behind the efficacy of CSWT in the treatment of CHD. The differentiation, proliferation and function of circulating EPCs are closely associated with growth factors, including VEGF and other cytokines (26-28). To evaluate whether the cytokines were involved in the CSWT-induced EPC differentiation and proliferation, the levels of four cytokines, including VEGF, IL-8, SDF-1 and MMP-9, were measured in the PB of CHD patients. Among the growth factors, VEGF is the most critical factor for vasculogenesis and angiogenesis (29-31), and the VEGF levels 
in the PB were found to be significantly increased following treatment in the present study (Fig. 1). The results were consistent with the findings in a chronic ischemia pig model and human umbilical vascular endothelial cells $(5,32)$. The observed increase in VEGF levels in the PB following CSWT, accompanied by the increase in the numbers and colonies of EPCs, as well as the circulating EPC numbers, indicated that CSWT contributed to the multiplication and differentiation of EPCs.

IL-8, a type of small peptide molecule, promotes angiogenesis by increasing cell contraction and enlarging gaps between flanking cells. IL-8 also leads to protein phosphorylation downstream by activating the Ras and mitogen-activated protein kinase pathway, which then mediates cell migration, adhesion and paracrine activity (33-35). IL-8 participates in the recruitment of EPCs in the myocardium from the circulation and increases their homing capacity in the ischemic myocardium, thereby promoting tissue regeneration and favorably affecting cardiac remodeling (36). In the present study, the IL-8 levels were significantly increased following CSWT. It is possible that the increase in IL- 8 not only triggered the proliferation of EPCs, but also resulted in EPC recruitment. The present findings showed that IL- 8 was induced by CSWT in CHD patients and that, in addition to VEGF, IL-8 was involved in the increase in EPC multiplication and differentiation caused by CSWT.

Similarly to IL-8, SDF-1 has been shown to induce neovascularization through the recruitment of EPCs into ischemic tissue $(36,37)$. The changes in SDF-1 following CSWT in the present study were not found to be significant. This may have been due to the fact that the secreted IL- 8 was sufficient to induce the EPCs, making an increase in SDF-1 unnecessary. Another reason may be that measurements were not made at the time-point corresponding to a significant increase in SDF-1. In a study of patients with acute myocardial infarction, the SDF-1 expression level was reported to reach a peak in the PB 17 days after CSWT (38). A perceptible SDF-1 expression change may have been missed in the present study, as the SDF-1 levels were tested 30 days after CSWT. This requires confirmation in future studies. The MMP-9 content in the PB also showed no significant change following CSWT. The MMP-9-induced migration of EPCs is regulated by SDF-1 (39); since the change in SDF-1 in the present study was minimal, it is reasonable that the change in MMP-9 was also found to lack significance.

In conclusion, the clinical symptoms of CHD were found to be alleviated after 3 months of CSWT in the present study. The effect of CSWT on CHD was indicated by several aspects of the study. First, CSWT promoted an increase in the level of VEGF in the ischemic myocardium, which led to an increase in the number of EPCs and promoted the survival and migration of EPCs, as well as lumen formation and conglutination and the synthesis and secretion of growth factors. Secondly, CSWT induced an increase in the level of IL-8 in the ischemic myocardium, which induced the recruitment of EPCs into the ischemic tissue. Notably, although the levels of SDF-1 and MMP-9 showed little change during the CSWT, the effect of CSWT on the SDF-1 and MMP-9 expression can not be ruled out, as the peaks of SDF-1 and MMP-9 expression may have been missed due to the short therapeutic period and the time limitations of the sampling. The type of mobilizing factor responsible for inducing the decisive increase in EPCs remains unclear and warrants further study. In addition, further research should be conducted into the signal transduction pathways associated with the growth factors involved in the promotion of the proliferation and differentiation of the EPCs.

\section{Acknowledgments}

This study was supported by The National Natural Science Foundation of China (no. 81260027), Technology Department Program of Yunnan Province (no. 2014FZ023) and the Health Department Program of Yunnan Province (no. 2012WS0005).

\section{References}

1. Gaziano T, Reddy KS, Paccaud F, Horton S, Chaturvedi V: Cardiovascular Disease. In: Disease Control Priorities in Developing Countries. 2nd edition. World Bank, Washington DC, 2006.

2. Bonow RO, Smaha LA, Smith SC Jr, Mensah GA and Lenfant C: World Heart Day 2002: The international burden of cardiovascular disease: Responding to the emerging global epidemic Circulation 106: 1602-1605, 2002.

3. World Health Organization: Program Fact Sheet no. 310: The top 10 causes of death. http://www.who.int/mediacentre/factsheets/fs310/en/index.html. Accessed January 6, 2010.

4. Fan L, Ma J, Chen YH and Chen XQ: Antioxidant and antimicrobial phenolic compounds from Setaria viridis. Chem Nat Comp 3: 433-437, 2014.

5. Nishida T, Shimokawa H, Oi K, Tatewaki H, Uwatoku T, Abe K, Matsumoto Y, Kajihara N, Eto M, Matsuda T, et al: Extracorporeal cardiac shock wave therapy ameliorates ischemia-induced myocardial dysfunction in pigs in vivo. Circulation 110: 3055-3061, 2004.

6. Fukumoto Y, Ito A, Uwatoku T, Matoba T, Kishi T, Tanaka H, Takeshita A, Sunagawa K and Shimokawa H: Extracorporeal cardiac shock wave therapy ameliorates myocardial ischemia in patients with severe coronary artery disease. Coron Artery Dis 17: 63-70, 2006.

7. Uwatoku T, Ito K, Abe K, Qi K, Hizume T, Sunagawa K and Shimokawa H: Extracorporeal cardiac shock wave therapy improves left ventricular remodeling after acute myocardial infarction in pigs. Coron Artery Dis 18: 397-404, 2007.

8. Shimokawa H, Ito K, Fukumoto Y and Yasuda S: Extracorporeal cardiac shock wave therapy for ischemic heart disease. Shock Waves 17: 449-455, 2008.

9. Khattab AA, Brodersen B, Schuermann-Kuchenbrandt D, Beurich H, Tölg R, Geist V, Schäfer T and Richardt G: Extracorporeal cardiac shock wave therapy: First experience in the everyday practice for treatment of chronic refractory angina pectoris. Int J Cardiol 121: 84-85, 2007.

10. Yang P, Guo T, Wang W, Peng YZ, Wang Y, Zhou P, Luo ZL, Cai HY, Zhao L and Yang HW: Randomized and double-blind controlled clinical trial of extracorporeal cardiac shock wave therapy for coronary heart disease. Heart Vessels 28: 284-291, 2013.

11. Ito Y, Ito K, Shiroto T, Tsuburaya R, Yi GJ, Takeda M, Fukumoto Y, Yasuda $S$ and Shimokawa H: Cardiac shock wave therapy ameliorates left ventricular remodeling after myocardial ischemia-reperfusion injury in pigs in vivo. Coron Artery Dis 21: 304-311, 2010.

12. Fu M, Sun CK, Lin YC, Wang CJ, Wu CJ, Ko SF, Chua S, Sheu JJ, Chiang CH, Shao PL, et al: Extracorporeal shock wave therapy reverses ischemia-related left ventricular dysfunction and remodeling: Molecular-cellular and functional assessment. PLoS One 6: e24342, 2011.

13. Schaufelberger M and Swedberg K: Is 6-minute walk test of value in congestive in heart failure? Am Heart J 136: 371-372, 1998.

14. Spertus JA, Winder JA, Dewhurst TA, Deyo RA, Prodzinski J, McDonell M and Fihn SD: Development and evaluation of the Seattle Angina Questionnaire: A new functional status measure for coronary artery disease. J AM Coll Cardiol 25: 333-341, 1995.

15. Chen XQ, Wang QQ, Li JM, Wang YQ, Zhang XZ and Li K: Comparison of simultaneous distillation and extraction, static headspace and headspace-solid phase microextraction coupled with GC/MS to measure the flavour components of Tricholoma matsutake. Asian J Chem 25: 6059-6063, 2013. 
16. Nurzynska D, Di Meglio F, Castaldo C, Arcucci A, Marlinghaus E, Russo S, Corrado B, de Santo L, Baldascino F, Cotrufo M and Montagnani S: Shock waves activate in vitro cultured progenitors and precursors of cardiac cell lineages from the human heart. Ultrasound Med Biol 34: 334-342, 2008.

17. Kikuchi Y, Ito K, Ito Y, Shiroto T, Tsuburaya R, Aizawa K, Hao K, Fukumoto Y, Takahashi J, Takeda M, et al: Double-blind and placebo-controlled study of the effectiveness and safety of extracorporeal cardiac shock wave therapy for severe angina pectoris. Circ J 74: 589-591, 2010.

18. Wang CJ, Wang FS, Yang KD, Weng LH, Hsu CC, Huang CS and Yang LC: Shock wave therapy induces neovascularization at the tendon-bone junction. A study in rabbits. J Orthop Res 21 : 984-989, 2003

19. Wang Y, Guo T, Cai HY, Ma TK, Tao SM, Sun S, Chen MQ, Gu Y, Pang JH, Xiao JM, et al: Cardiac shock wave therapy reduces angina and improves myocardial function in patients with refractory coronary artery disease. Clin Cardiol 33: 693-699, 2010.

20. Wang Y, Guo T, Ma TK, Cai HY, Tao SM, Peng YZ, Yang P, Chen MQ and Gu Y: A modified regimen of extracorporeal cardiac shock wave therapy for treatment of coronary artery disease. Cardiovasc Ultrasound 10: 35, 2012.

21. Vasa M, Fichtlscherer S, Aicher A, Adler K, Urbich C, Martin H, Zeiher AM and Dimmeler S: Number and migratory activity of circulating endothelial progenitor cells inversely correlate with risk factors for coronary artery disease. Circ Res 89: E1-E7, 2001.

22. Hill JM, Zalos G, Halcox JP, Schenke WH, Waclawiw MA, Quyyumi AA and Finkel T: Circulating endothelial progenitor cells, vascular function, and cardiovascular risk. N Engl J Med 348: 593-600, 2003

23. Schmidt-Lucke C, Rössig L, Fichtlscherer S, Vasa M, Britten M, Kämper U, Dimmeler S and Zeiher AM: Reduced number of circulating endothelial progenitor cells predicts future cardiovascular events: Proof of concept for the clinical importance of endogenous vascular repair. Circulation 111: 2981-2987, 2005.

24. Igarashi J, Miyoshi M, Hashimoto T, Kubota Y and Kosaka H: Statins induce S1P1 receptors and enhance endothelial nitric oxide production in response to high-density lipoproteins. $\mathrm{Br}$ J Pharmacol 150: 470-479, 2007.

25. Thurston G, Rudge JS, Ioffe E, Zhou H, Ross L, Croll SD Glazer N, Holash J, McDonald DM and Yancopoulos GD Angiopoietin-1 protects the adult vasculature against plasma leakage. Nat Med 6: 460-463, 2000.

26. Asahara T, Takahashi T, Masuda H, Kalka C, Chen D, Iwaguro H, Inai Y, Silver M and Isner JM: VEGF contributes to postnatal neovascularization by mobilizing bone marrow-derived endothelial progenitor cells. EMBO J 18: 3964-3972, 1999.

27. Gehling UM, Ergün S, Schumacher U, Wagener C, Pantel K, Otte M, Schuch G, Schafhausen P, Mende T, Kilic N, et al: In vitro differentiation of endothelial cells from AC133-positive progenitor cells. Blood 95: 3106-3112, 2000.

28. Hattori K, Dias S, Heissig B, Hackett NR, Lyden D, Tateno M, Hicklin DJ, Zhu Z, Witte L, Crystal RG, et al: Vascular endothelial growth factor and angiopoietin-1 stimulate postnatal hematopoiesis by recruitment of vasculogenic and hematopoietic stem cells. J Exp Med 193: 1005-1014, 2001.
29. Carmeliet P, Ferreira V, Breier G, Pollefeyt S, Kieckens L, Gertsenstein M, Fahrig M, Vandenhoeck A, Harpal K, Eberhardt C, et al: Abnormal blood vessel development and lethality in embryos lacking a single VEGF allele. Nature 380: 435-439, 1996.

30. Ferrara N, Carver-Moore K, Chen H, Dowd M, Lu L, O'Shea KS, Powell-Braxton L, Hillan KJ and Moore MW: Heterozygous embryonic lethality induced by targeted inactivation of the VEGF gene. Nature 380: 439-442, 1996

31. Shalaby F, Rossant J, Yamaguchi TP, Gertsenstein M, Wu XF, Breitman ML and Schuh AC: Failure of blood-island formation and vasculogenesis in Flk-1-deficient mice. Nature 376: 62-66, 1995.

32. Gutersohn A, Caspari G and Erbel R: Upregulation of Vascular endothelial growth factor m-RNA in Human umbilical vascular endothelial cells via shock waves. Eur J Heart Fail 2 (Suppl 1): 42, 2000.

33. Kupatt C,Hinkel R, Pfosser A, El-Aouni C, Wuchrer A, Fritz A, Globisch F, Thormann M, Horstkotte J, Lebherz C, et al: Cotransfection of vascular endothelial growth factor-A and platelet-derived growth factor-B via recombinant adeno-associated virus resolves chronic ischemic malperfusion role of vessel maturation. J Am Coll Cardiol 56: 414-422, 2010

34. Urao N, Inomata $\mathrm{H}$, Razvi $\mathrm{M}$, Kim HW, Wary K, McKinney R, Fukai $\mathrm{T}$ and Ushio-Fukai M: Role of nox2-based NADPH oxidase in bone marrow and progenitor cell function involved in neovascularization induced by hindlimb ischemia. Circ Res 103: 212-220, 2008

35. Lund T, Hermansen SE, Andreasen TV, Olsen JO, Østerud B, Myrmel T and Ytrehus K: Shear stress regulates inflammatory and thrombogenic gene transcripts in cultured human endothelial progenitor cells. Thromb Haemost 104: 582-591, 2010.

36. Kocher AA, Schuster MD, Bonaros N, Lietz K, Xiang G, Martens TP, Kurlansky PA, Sondermeijer H, Witkowski P, Boyle A, et al: Myocardial homing and neovascularization by human bone marrow angioblasts is regulated by IL-8/Gro CXC chemokines. J Mol Cell Cardiol 40: 455-464, 2006.

37. De Falco E, Porcelli D, Torella AR, Straino S, Iachininoto MG, Orlandi A, Truffa S, Biglioli P, Napolitano M, Capogrossi MC and Pesce M: SDF-1 involvement in endothelial phenotype and ischemia-induced recruitment of bone marrow progenitor cells. Blood 104: 3472-3482, 2004.

38. Huang PH, Chen YH, Wang $\mathrm{CH}$, Chen JS, Tsai HY, Lin FY, Lo WY, Wu TC, Sata M, Chen JW and Lin SJ: Matrix metalloproteinase-9 is essential for ischemia-induced neovascularization by modulating bone marrow-derived endothelial progenitor cells. Arterioscler Thromb Vasc Biol 29: 1179-1184, 2009.

39. Valenzuela-Fernández A, Planchenault T, Baleux F, Staropoli I, Le-Barillec K, Leduc D, Delaunay T, Lazarini F, Virelizier JL, Chignard M, et al: Leukocyte elastase negatively regulates Stromal cell-derived factor-1(SDF-1)/CXCR4 binding and functions by amino-terminal processing of SDF-1 and CXCR4. J Biol Chem 277: 15677-15689, 2002. 